Supplementary Information

\title{
Library Screening to Identify Highly-Effective Autophagy Inhibitor for Improving Photothermal Cancer Therapy
}

Li Wang ${ }^{1}$, Yitong Wang ${ }^{2}$, Wei Zhao ${ }^{3}$, Kaili Lin ${ }^{2}$, Wei $\mathrm{Li}^{3, *}$, Guodong Wang ${ }^{3, *}$ and Qiang Zhang ${ }^{1, *}$

${ }^{1}$ Shanghai Key Laboratory of Regulatory Biology, School of Life Sciences, East China Normal University, Shanghai, 200241, P.R. China

${ }^{2}$ Department of Oral \& Cranio-Maxillofacial Surgery, Shanghai Ninth People's Hospital, College of Stomatology, Shanghai Jiao Tong University; School of Medicine; National Clinical Research Center for Oral Diseases; Shanghai Key Laboratory of Stomatology \& Shanghai Research Institute of Stomatology, Shanghai 200011, P.R. China

${ }^{3}$ Department of Stomatology, Changzheng Hospital, Second Military Medical University, Shanghai, 200003, P. R. China

*Correspondence should be addressed to Q. Z. (E-mail: qzhang@bio.ecnu.edu.cn); G. W. (E-mail: wangguodong@smmu.edu.cn); W. L. (E-mail: li_wei_sh@hotmail.com) 


\section{Experimental section}

Materials. Pyrvinium, metformin, vitexin, celecoxib, pantoprazole, liensinine, Z-ligustilide, DAC, DAS, fingolimod, and dichloroacetate were purchased from Energy Chemical (Shanghai, China). Lycorine, LY294002, tanespimycin, ICG, and polyvinyl alcohol were obtained from Macklin Biochemical Co., Ltd (Shanghai, China). Dorsomorphin, SP600125, 3-methyladenine, wortmannin, CQ, HCQ, 1-ethyl-3(3-dimethylaminopropyl) carbodiimide (EDC), and Nhydroxysuccinimide (NHS) were purchased from Sigma-Aldrich Trading Co., Ltd (Shanghai, China). Ethanol, acetone, dimethyl sulfoxide (DMSO), xylene, hydrochloric acid, and dichloromethane were obtained from Shanghai Titan Scientific Co., Ltd (Shanghai, China). The acid-terminated PLGA (lactide: glycolide $=50: 50, \mathrm{Mw}=38000-54000 \mathrm{Da}$ ) and maleimide-linked PEG-amine (MAL-PEG-NH2, Mw = 2000 Da) were purchased from Shanghai Aladdin Biochemical Technology Co., Ltd (Shanghai, China).

Synthesis of PLGA-PEG. PLGA-PEG was obtained via a one-step reaction. Briefly, $400 \mathrm{mg}$ PLGA in $4.5 \mathrm{~mL}$ DMSO and $8.3 \mathrm{mg}$ EDC in $0.4 \mathrm{~mL} \mathrm{DMSO}$ were mixed under magnetic stirring. $1.0 \mathrm{mg}$ NHS in $0.1 \mathrm{~mL}$ DMSO was added to the solution after stirring for $10 \mathrm{~min} .2 \mathrm{~h}$ later, $86.8 \mathrm{mg}$ MALPEG-NH2 in $1.0 \mathrm{~mL}$ DMSO was added. $24 \mathrm{~h}$ later, the product was dialyzed against DI water and then lyophilized. The purified sample was stored at $4{ }^{\circ} \mathrm{C}$ for use.

Preparation of nanodrugs. P-D/I were prepared using a double emulsion solvent evaporation method. In a typical preparation, $0.4 \mathrm{~mL}$ of $5 \mathrm{mg} / \mathrm{mL}$ ICG aqueous solution (the internal water phase) was added in $1 \mathrm{~mL}$ of dichloromethane and acetone mixed solvent (volume ratio $=1: 1$, the organic phase) that contained $20 \mathrm{mg}$ of PLGA-PEG and $0.5 \mathrm{mg}$ of DAS. The first emulsification was performed in an ice bath using an ultrasonic cell disruptor $(50 \mathrm{~W}, 1 \mathrm{~min}$, VCX150, Sonics \& Materials Inc., USA). The primary emulsion (W/O) was dropwise added into $5 \mathrm{~mL}$ of $1 \mathrm{wt} \%$ polyvinyl alcohol aqueous solution (the outer water phase). The second emulsification was performed in an ice bath using the ultrasonic cell disruptor (50 W, $2 \mathrm{~min}$ ). Dichloromethane in the nanoparticles was evaporated in a fume hood under magnetic stirring for $4 \mathrm{~h}$. The P-D/I were collected and purified via centrifugation $(15000 \mathrm{rpm}, 15 \mathrm{~min})$ at $4{ }^{\circ} \mathrm{C}$. P-I and P-D were prepared via the same method.

The yield of nanodrugs and their concentration in suspension. $1 \mathrm{~mL}$ of the as-prepared nanodrugs was dried by lyophilization and weighed. The yield of nanodrugs was calculated as 
follows:

$$
\text { Yield of nanodrugs }=\frac{\text { Dry weight of nanodrugs }}{\text { weight of added copolymers and drugs }} \times 100 \%
$$

The concentration of nanodrugs was calculated based on the formula:

$$
\text { Concentration of nanodrugs }(\mathrm{mg} / \mathrm{mL})=\frac{\text { Dry weight of nanodrugs }}{\text { Volume of suspension }}
$$

Loading ratio and encapsulation efficiency of nanodrugs. The freeze-dried P-D/I were disassembled in DMSO, and the concentrations of ICG and DAS were calculated based on their standard curves. Briefly, $10 \mathrm{mg}$ of freeze-dried P-D/I were dissolved in $1 \mathrm{~mL}$ DMSO. The solution was diluted 500 times for determining ICG concentration using an ultraviolet spectrophotometer (Cary 60, Agilent Technologies, USA), and it was diluted 10 times for determining DAS concentration using a high-performance liquid chromatograph (1200 Series, Agilent Technologies, USA). The absorbances of ICG at different concentrations were determined at $790 \mathrm{~nm}$ by using the ultraviolet spectrophotometer, and its standard curve was obtained via a linear regression analysis (Figure S12). The absorbances of DAS at different concentrations were determined at $284 \mathrm{~nm}$ by using the high-performance liquid chromatograph, and its standard curve was obtained via a linear regression analysis (Figure S13). The loading ratio of nanodrugs was calculated as follows:

$$
\text { Loading ratio of nanodrugs }=\frac{\text { Weight of ICG or DAS in nanodrugs }}{\text { Weight of freeze }- \text { dried nanodrugs }} \times 100 \%
$$

The encapsulation efficiency of nanodrugs was calculated as follows:

$$
\text { Encapsulation efficiency of nanodrugs }=\frac{\text { Weight of ICG or DAS in nanodrugs }}{\text { Weight of added ICG or DAS }} \times 100 \%
$$

Characterizations. The TEM images of nanodrugs were obtained by using a microscope (120 KV, HT7700, Hitachi, Japan), and the HR-TEM images of nanodrugs were taken by using a microscope (200 KV, HT7700, Hitachi, Japan). The hydrodynamic sizes and zeta potentials of nanodrugs were measured by using an instrument of Zetasizer Nano ZS90 (Malvern, UK). The FTIR spectra were collected by using a Nicolet iS50 spectroscope (Thermo Fisher Scientific, USA).

Photothermal effect of nanodrugs. In a typically assay, $1 \mathrm{~mL}$ aqueous suspension of P-I (268.32 $\mu \mathrm{g} / \mathrm{mL}, 13.87 \mu \mathrm{g} / \mathrm{mL}$ for ICG), P-D (257.51 $\mu \mathrm{g} / \mathrm{mL}, 3.06 \mu \mathrm{g} / \mathrm{mL}$ for DAS) or P-D/I (271.38 $\mu \mathrm{g} / \mathrm{mL}$, $3.06 \mu \mathrm{g} / \mathrm{mL}$ for DAS, $13.87 \mu \mathrm{g} / \mathrm{mL}$ for ICG) hold in a cuvette was irradiated by a NIR laser (MDLeIIIe808, Changchun New Industries Optoelectronics Technology Co., Ltd. China) at 0.25 $\mathrm{W} / \mathrm{cm}^{2}$ for $2 \mathrm{~min}$. The temperatures were recorded with an infrared thermal imaging camera 
(Magnity Electronics, China).

Drug release of nanodrugs. In a typical assay, $10 \mathrm{~mL}$ of fresh-prepared P-D/I $(1.50 \mathrm{mg} / \mathrm{mL}, 17.80$ $\mu \mathrm{g} / \mathrm{mL}$ for DAS, $80.80 \mu \mathrm{g} / \mathrm{mL}$ for ICG) were suspended in PBS ( $\mathrm{pH}=7.4)$. The solution was stirred at room temperature. At the time points of $0,0.5,1,2,4,8,12,24,48$, and $72 \mathrm{~h}, 0.5 \mathrm{~mL}$ liquid was taken out, and the solid was collected via centrifugation $15000 \mathrm{rpm}, 5 \mathrm{~min}$ ), and then was dissolved in $100 \mu \mathrm{L}$ of DMSO. The concentrations of ICG and DAS were determined according to the method described in the loading ratio and encapsulation efficiency of nanodrugs.

Moreover, the drug release behavior of DAS and ICG in P-D/I under NIR irradiation $\left(0.5 \mathrm{~W} / \mathrm{cm}^{2}\right.$, $30 \mathrm{~min})$ was assessed. In a typical assay, $10 \mathrm{~mL}$ of fresh-prepared P-D/I $(1.50 \mathrm{mg} / \mathrm{mL}, 17.80 \mu \mathrm{g} / \mathrm{mL}$ for DAS, $80.80 \mu \mathrm{g} / \mathrm{mL}$ for ICG) were suspended in PBS $(\mathrm{pH}=7.4)$ and stirred at room temperature. The solution was irradiated by a NIR laser at $0.5 \mathrm{~W} / \mathrm{cm}^{2}$ for $30 \mathrm{~min}$ and followed by an interval of $30 \mathrm{~min}$. The procedure was performed four times. At the time points of $0,0.5,1,1.5,2,2.5,3,3.5$, and $4 \mathrm{~h}, 0.5 \mathrm{~mL}$ of liquid was taken out, and the solid was collected via centrifugation (15000 rpm, $5 \mathrm{~min}$ ), and then was dissolved in $100 \mu \mathrm{L}$ of DMSO. The concentrations of ICG and DAS were determined according to the method described in "Loading ratio and encapsulation efficiency of nanodrugs".

Stability of ICG in the nanodrugs. $2 \mathrm{~mL}$ of $10 \mu \mathrm{g} / \mathrm{mL}$ ICG solution or $0.19 \mathrm{mg} / \mathrm{mL} \mathrm{P-D/I}$ suspension $\left(10.00 \mu \mathrm{g} / \mathrm{mL}\right.$ for ICG, $2.19 \mu \mathrm{g} / \mathrm{mL}$ for DAS) in PBS was placed in a $37^{\circ} \mathrm{C}$ oven for 48 $\mathrm{h}$. At the time points of $0,12,24$, and $48 \mathrm{~h}$, the UV absorption spectrum of the liquid was collected by using an ultraviolet spectrophotometer (Cary 60, Agilent Technologies, USA).

Cell culture. Cancer cell lines of MDA-MB231 (ATCC) and GFP-LC3/HeLa (provided as a gift by Prof. Longping Wen) were cultured in a DMEM medium containing $10 \%$ FBS and $1 \%$ penicillinstreptomycin, and incubated at $37{ }^{\circ} \mathrm{C}$ in a humidified atmosphere of $5 \% \mathrm{CO} 2$.

Determination of the non-toxic therapeutic dose of autophagy inhibitors and ICG. MDAMB231 cells were seeded in a 96-well plate at a density of 8000 cells per well. After overnight culture, the cells were incubated with different concentrations of autophagy inhibitors or ICG for $15 \mathrm{~h}$, and then the cell viabilities were measured by the MTT assay. The dose-effect curves of 20 autophagy inhibitors were collected (Figure S1-7). According to the data, the non-toxic therapeutic doses (cell viability above $90 \%$ ) for 20 autophagy inhibitors were determined (Table S1). The doseeffect curves of ICG and the photothermal effect of ICG under NIR irradiation $\left(0.5 \mathrm{~W} / \mathrm{cm}^{2}, 5 \mathrm{~min}\right)$ 
were shown in (Figure S8). The non-toxic therapeutic dose of ICG was determined to be $20 \mu \mathrm{M}$ $(15.50 \mu \mathrm{g} / \mathrm{mL})$.

Photothermal killing of cancer cells. MDA-MB231 cells were seeded in a 96-well plate at a density of 4000 cells per well. After overnight incubation, the culture media were replaced by fresh ones containing different concentrations of ICG $(0,2.5,5,10,20,40$, and $60 \mu \mathrm{M})$, and then the cells were irradiated by a NIR laser at $0.5 \mathrm{~W} / \mathrm{cm}^{2}$ for $5 \mathrm{~min}$. After that, the cells were incubated with new culture media for $24 \mathrm{~h}$, and then their viabilities were determined by the MTT assay.

Autophagy inhibitor-sensitized photothermal killing of cancer cells. In a typical assay, MDAMB231 cells seeded in a 96-well plate at a density of 4000 cells per well were incubated overnight. The cells were divided into five groups including control, inhibitor, ICG, ICG+NIR, and inhibitor/ICG+NIR groups, and received the different treatments as the group named indicated. The cells in the groups of ihibitor and inhibitor/ICG+NIR were pre-incubated with different autophagy inhibitors at their non-toxic concentrations (as shown in Table S1) for $15 \mathrm{~h}$. After that, the cells in the groups of ICG, ICG+NIR, and inhibitor/ICG+NIR were treated with $20 \mu \mathrm{M}$ ICG. Immediately, the cells in ICG+NIR and inhibitor/ICG+NIR groups were irradiated by a NIR laser at 0.50 or 0.25 $\mathrm{W} / \mathrm{cm}^{-2}$ for $5 \mathrm{~min}$. Subsequently, the cells were incubated with new culture medial for $24 \mathrm{~h}$, and then their viabilities were determined by the MTT assay.

In a nanodrug-associated assay, the same procedure was conducted. The concentrations of nanodrugs were $257.51 \mu \mathrm{g} / \mathrm{mL}$ for P-D (3.06 $\mu \mathrm{g} / \mathrm{mL}$ for DAS), $268.32 \mu \mathrm{g} / \mathrm{mL}$ for P-I (13.87 $\mu \mathrm{g} / \mathrm{mL}$ for ICG), $271.38 \mu \mathrm{g} / \mathrm{mL}$ for P-D/I (13.87 $\mu \mathrm{g} / \mathrm{mL}$ for ICG, $3.06 \mu \mathrm{g} / \mathrm{mL}$ for DAS). The NIR irradiation was conducted at $0.25 \mathrm{~W} / \mathrm{cm}^{-2}$.

GFP-LC3 dot observation. GFP-LC3/HeLa cells seeded on laser confocal dishes at an appropriate density were incubated overnight. The cells were then treated with the same procedure as above. The fluorescence imaging was observed using a confocal laser scanning microscope (TCS SP8, Leica, Germany).

Western blotting assay. MDA-MB231 cells in 6-well plates were treated with the same procedure as above. The western blotting assay was conducted according to a standard protocol. The nitrocellulose membrane was finally incubated with LC3B or $\beta$-Actin rabbit monoclonal antibodies (Cell Signaling Technology, USA), and then incubated with a fluorescence-labeled secondary antibody of anti-rabbit IgG (H+L (Cell Signaling Technology, USA). The imaging data were further 
analyzed using an infrared spectrometer (LI-COR, Odyssey, USA).

Annexin V-FITC/PI apoptosis detection assay. MDA-MB231 cells in 6-well plates were harvested after different treatments. The cells were stained following the protocol of Annexin VFITC/PI apoptosis detection kit (Sigma-Aldrich) and then were analyzed by a flow cytometer (BD LSRFortessa SORP, USA).

Cellular uptake of nanodrugs. GFP-LC3/HeLa cells seeded in a laser confocal dish were incubated with P-D/I nanoparticles (271.38 $\mu \mathrm{g} / \mathrm{mL}, 3.06 \mu \mathrm{g} / \mathrm{mL}$ for DAS, $13.87 \mu \mathrm{g} / \mathrm{mL}$ for ICG) for $15 \mathrm{~h}$. After that, the culture media were replaced by fresh ones, and the cells were irradiated by a NIR laser $\left(0.25 \mathrm{~W} / \mathrm{cm}^{2}\right)$ for $5 \mathrm{~min}$. Finally, the cells were immediately observed using a confocal laser scanning microscope.

Autophagy inhibition-associated photothermal treatment of tumors. All the animal experiments were performed with the guide of the National Institutes of Health Guidelines and approved by the ethics committee of the East China Normal University. BALB/c nude female mice (about $20 \mathrm{~g}$ ) were used to establish the subcutaneous tumor model. Briefly, MDA-MB231 cells (about $10^{6}$ cells) in $100 \mu \mathrm{L}$ PBS were injected into the flanks of each mouse. After tumor volumes reaching 100-150 $\mathrm{mm}^{3}$, the mice were randomly assigned into five groups (four animals per group). The mice in the PBS group were injected with $250 \mu \mathrm{L}$ PBS. The mice in the P-D group were injected with $250 \mu \mathrm{L}$ P-D in PBS (14.18 mg/mL, $178 \mu \mathrm{g} / \mathrm{mL}$ for DAS). The mice in P-I+NIR group C were injected with $250 \mu \mathrm{L}$ P-I in PBS $(14.81 \mathrm{mg} / \mathrm{mL}, 808 \mu \mathrm{g} / \mathrm{mL}$ for ICG), and irradiated by a NIR laser. The mice in the P-D/I group were injected with $250 \mu \mathrm{L}$ P-D/I in PBS $(14.99 \mathrm{mg} / \mathrm{mL}, 808 \mu \mathrm{g} / \mathrm{mL}$ for ICG, 178 $\mu \mathrm{g} / \mathrm{mL}$ for DAS). The mice in the P-D/I+NIR group were injected with $250 \mu \mathrm{L} \mathrm{P-D/I}$ and then treated with NIR irradiation. The agents were injected every three days four times. The tumors were irradiated by a NIR laser $\left(1.0 \mathrm{~W} / \mathrm{cm}^{2}, 7 \mathrm{~min}\right) 12$ and $24 \mathrm{~h}$ after each injection. The tumor-site temperatures were recorded using an infrared thermal imaging camera. The tumor size and the body weight of mice were recorded every day.

TUNEL staining assay. The tumor was fixed in $4 \mathrm{wt} \%$ paraformaldehyde at room temperature for $24 \mathrm{~h}$ in dark. The tumor was embedded in paraffin after dehydration and clearing with xylene, and then was sectioned into slices with a thickness of $4.0 \mu \mathrm{m}$. The tumor section was analyzed by using a colorimetric TUNEL apoptosis assay kit (Shanghai Beyotime Biotechnology). According to the provided protocols, the tumor section was incubated with proteinase K, biotin-dUTP, streptavidin- 
horseradish peroxidase, and 3, 3-diaminobenzidine successively and then sealed with neutral resins. The tumor tissue was observed by using a microscope (IX73, Olympus Corporation, Japan).

Hematoxylin and eosin $(\mathbf{H} \& \mathbf{E})$ staining assay. The normal tissues and organs of mice were treated as above to obtain the paraffin slices. The slices were stained with hematoxylin and eosin and sealed with neutral resins. Finally, the tissues were observed by using a microscope. 


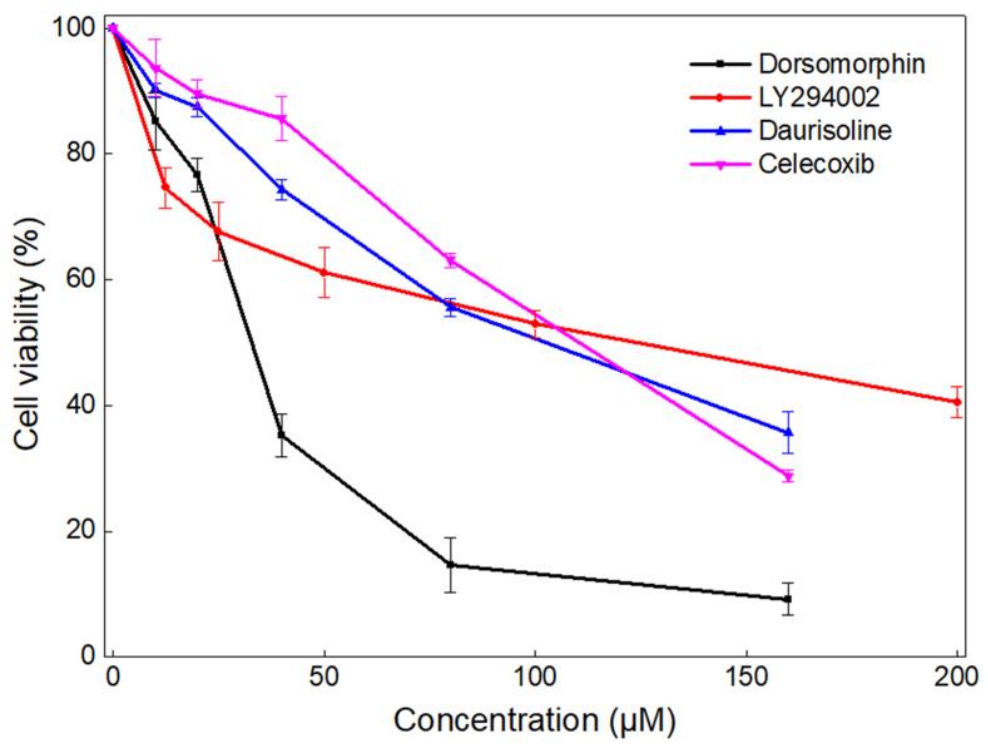

Figure S1. The dose-effect curves of dorsomorphin, LY294002, daurisoline (DAS), and celecoxib. 


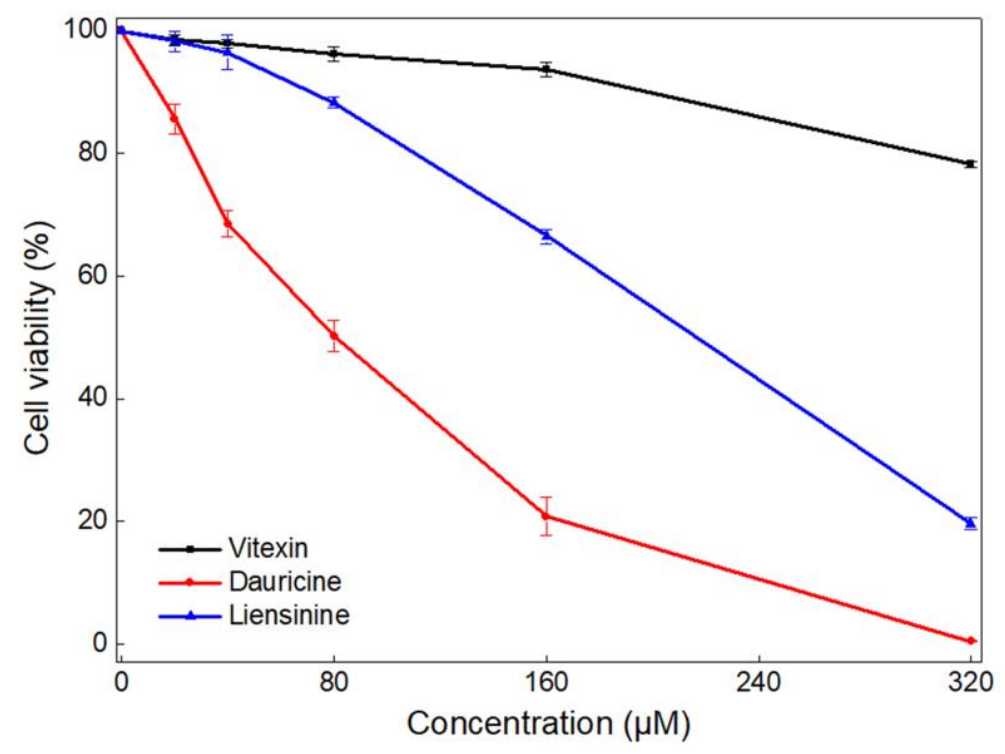

Figure S2. The dose-effect curves of vitexin, dauricine (DAC), and liensinine. 


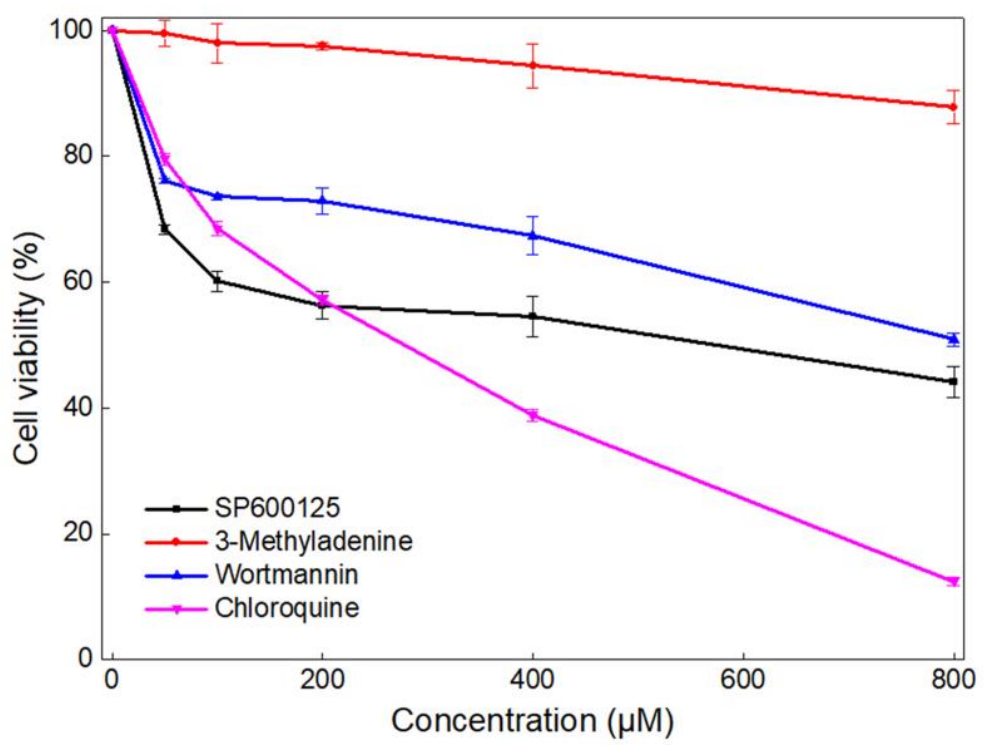

Figure S3. The dose-effect curves of SP600125, 3-methyladenine, wortmannin, and chloroquine (CQ). 


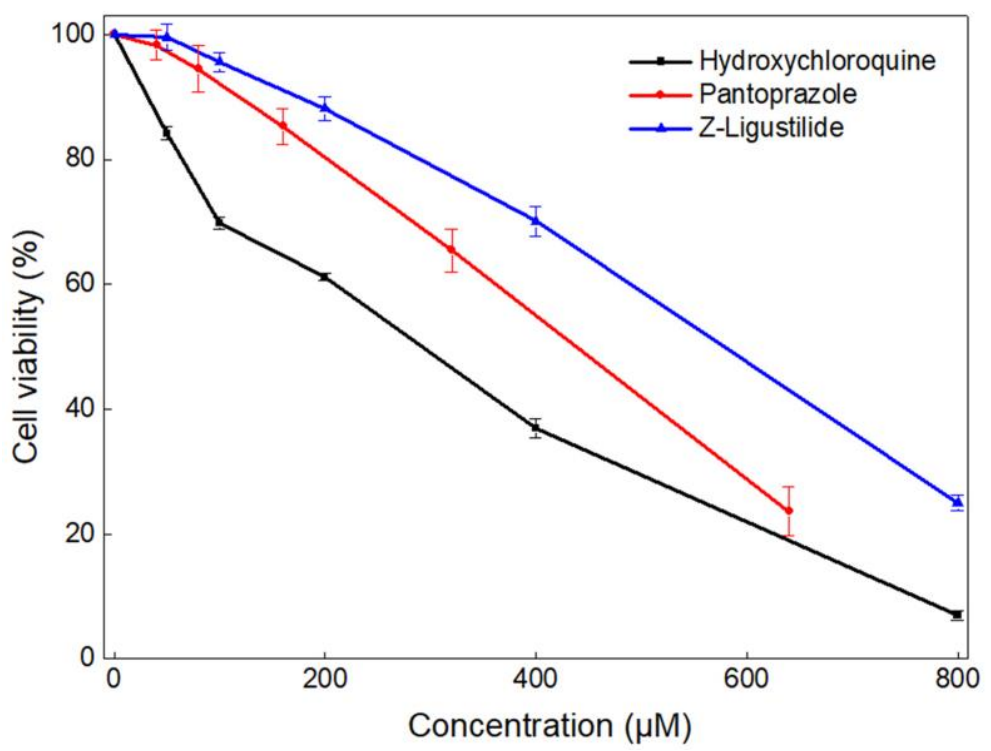

Figure S4. The dose-effect curves of hydroxychloroquine (HCQ), pantoprazole, and Z-ligustilide. 


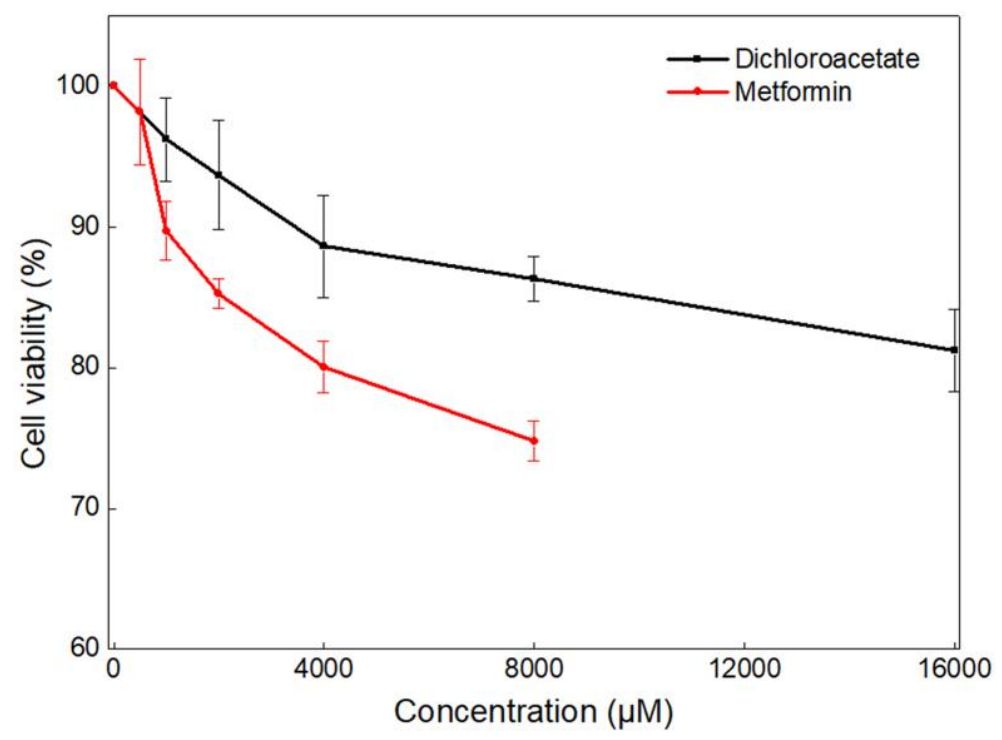

Figure S5. The dose-effect curves of dichloroacetate and metformin. 


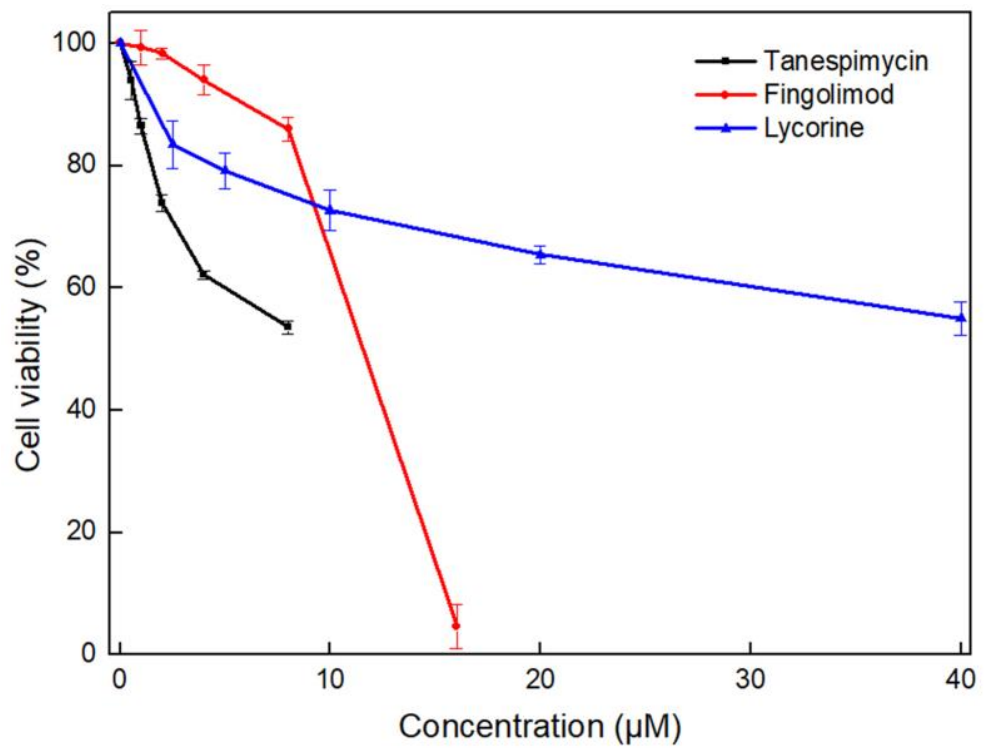

Figure S6. The dose-effect curves of tanespimycin, fingolimod, and lycorine. 


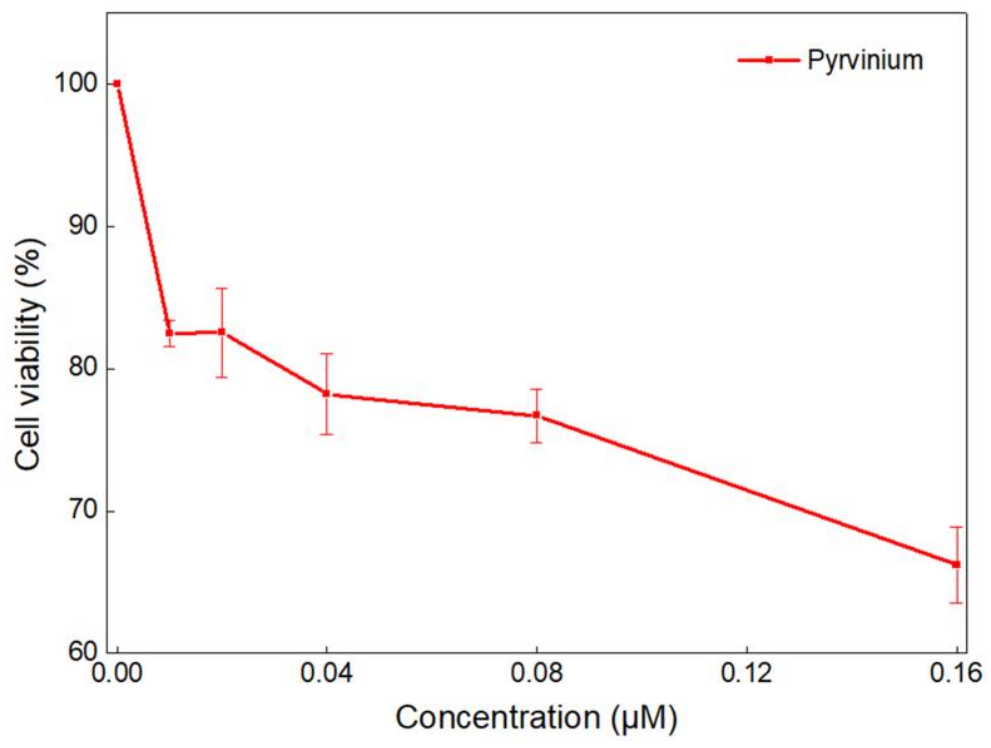

Figure S7. The dose-effect curve of pyrvinium. 
Table S1. The non-toxic therapeutic dose of twenty autophagy inhibitors.

\begin{tabular}{|l|l|l|l|l|l|}
\hline Inhibitors & Dorsomorphin & LY294002 & DAS & Celecoxib & Vitexin \\
\hline Dose & $4 \mu \mathrm{M}(1.60$ & $2 \mu \mathrm{M}$ & $5 \mu \mathrm{M}$ & $20 \mu \mathrm{M}$ & $80 \mu \mathrm{M}$ \\
& $\mu \mathrm{g} / \mathrm{mL})$ & $(0.61 \mu \mathrm{g} / \mathrm{mL})$ & $(3.06 \mu \mathrm{g} / \mathrm{mL})$ & $(7.63 \mu \mathrm{g} / \mathrm{mL})$ & $(46.28 \mu \mathrm{g} / \mathrm{mL})$ \\
\hline Inhibitors & $\mathrm{DAC}$ & Liensinine & SP600125 & 3 -methyladenine & Wortmannin \\
\hline Dose & $5 \mu \mathrm{M}$ & $50 \mu \mathrm{M}$ & $1.5 \mu \mathrm{M}$ & $100 \mu \mathrm{M}$ & $5 \mu \mathrm{M}$ \\
& $(3.12 \mu \mathrm{g} / \mathrm{mL})$ & $(30.54 \mu \mathrm{g} / \mathrm{mL})$ & $(0.33 \mu \mathrm{g} / \mathrm{mL})$ & $(14.92 \mu \mathrm{g} / \mathrm{mL})$ & $(2.14 \mu \mathrm{g} / \mathrm{mL})$ \\
\hline Inhibitors & $\mathrm{CQ}$ & $\mathrm{HCQ}$ & Pantoprazole & Z-Ligustilide & Dichloroacetate \\
\hline Dose & $20 \mu \mathrm{M}$ & $20 \mu \mathrm{M}$ & $80 \mu \mathrm{M}$ & $50 \mu \mathrm{M}$ & $1000 \mu \mathrm{M}$ \\
& $(6.40 \mu \mathrm{g} / \mathrm{mL})$ & $(6.72 \mu \mathrm{g} / \mathrm{mL})$ & $(30.67 \mu \mathrm{g} / \mathrm{mL})$ & $(9.51 \mu \mathrm{g} / \mathrm{mL})$ & $(150.92 \mu \mathrm{g} / \mathrm{mL})$ \\
\hline Inhibitors & Metformin & Tanespimycin & Fingolimod & Lycorine & Pyrvinium \\
\hline Dose & $500 \mu \mathrm{M}$ & $0.35 \mu \mathrm{M}$ & $4 \mu \mathrm{M}$ & $0.35 \mu \mathrm{M}$ & $0.005 \mu \mathrm{M}$ \\
& $(64.58 \mu \mathrm{g} / \mathrm{mL})$ & $(0.20 \mu \mathrm{g} / \mathrm{mL})$ & $(1.23 \mu \mathrm{g} / \mathrm{mL})$ & $(0.10 \mu \mathrm{g} / \mathrm{mL})$ & $(5.76 \mathrm{ng} / \mathrm{mL})$ \\
\hline
\end{tabular}




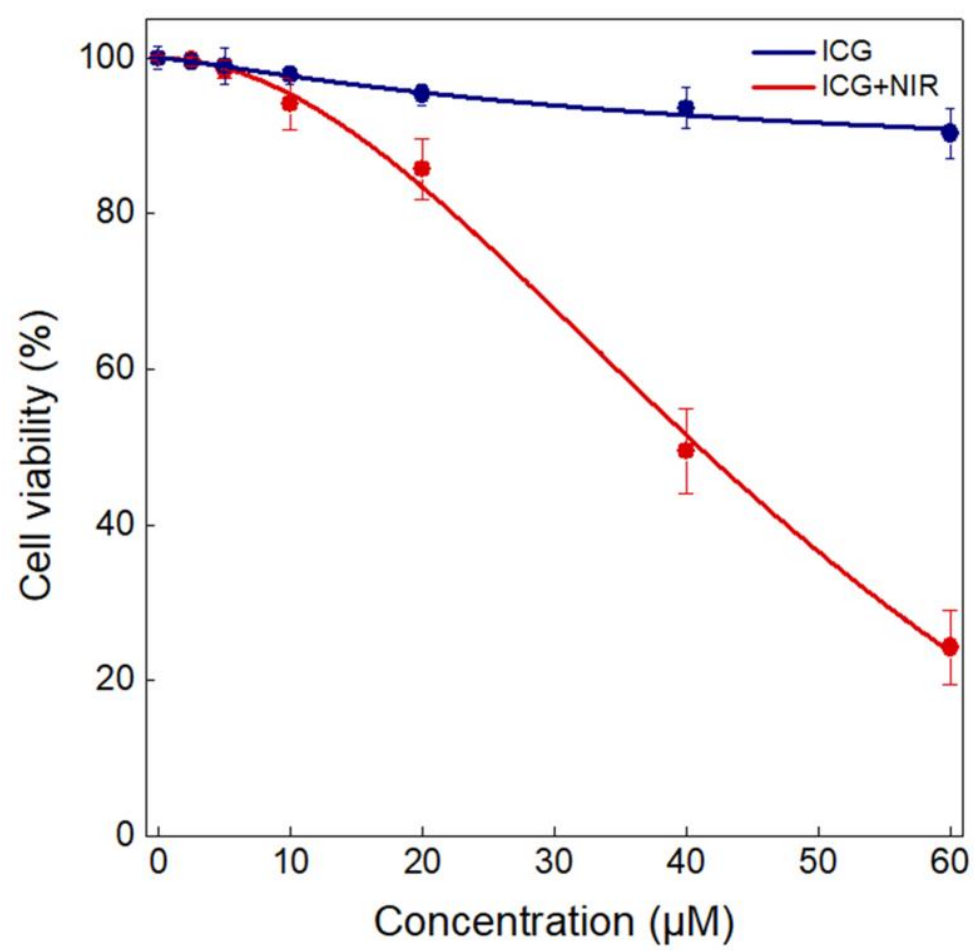

Figure S8. The dose-effect curves of ICG and ICG + NIR . 


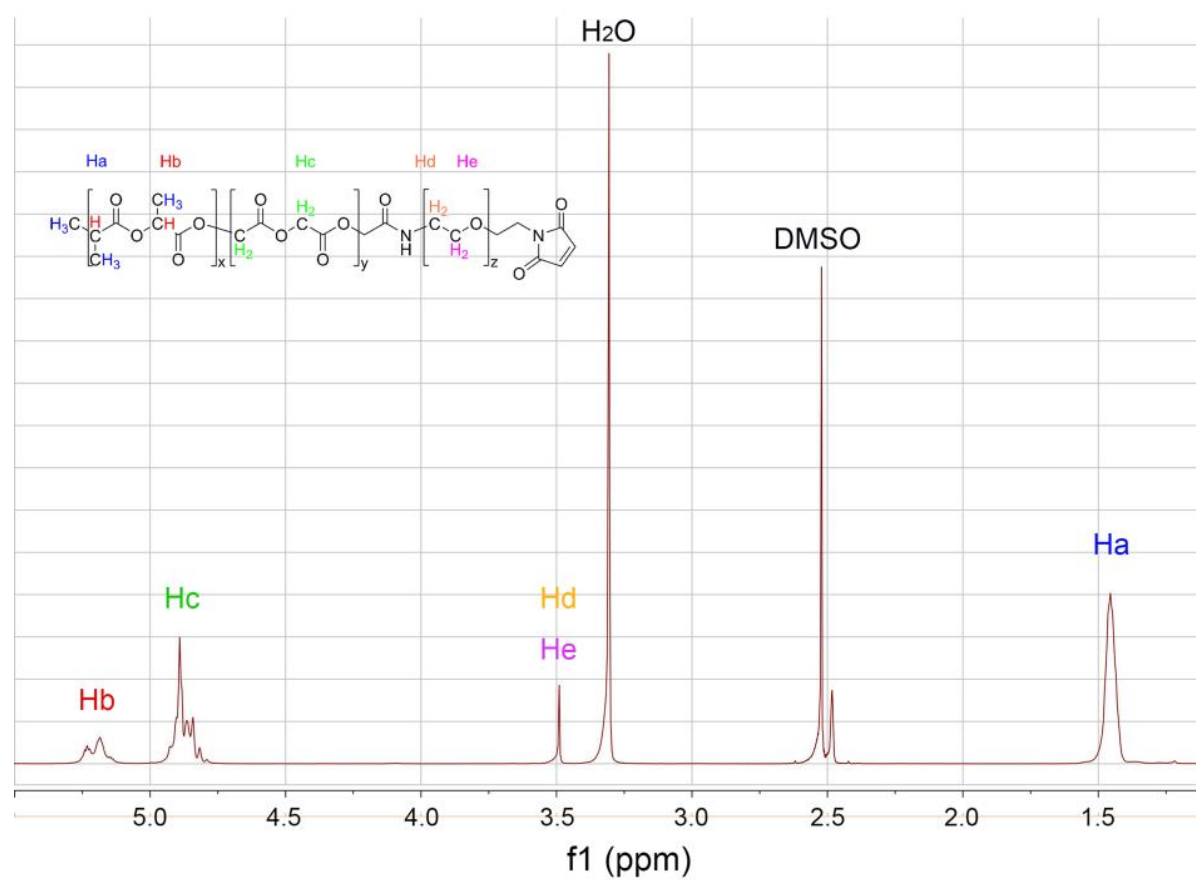

Figure S9. The ${ }^{1} \mathrm{H}-\mathrm{NMR}$ spectrum of PLGA-PEG copolymers. $\delta 5.20(\mathrm{~m}, \mathrm{Hb}), \delta 4.87(\mathrm{~m}, \mathrm{Hc}), \delta$ 3.49 (s, Hd and He), $\delta 3.31$ (s, H2O), $\delta 2.51$ (m, DMSO), $\delta 1.46$ (m, Ha). 

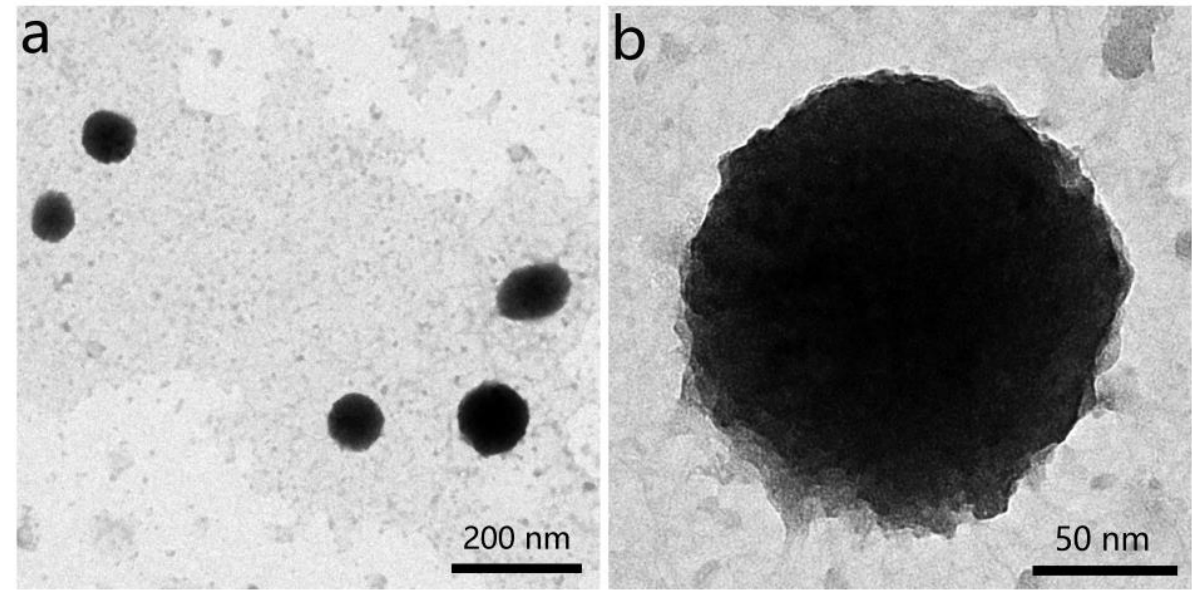

Figure S10. HR-TEM images of P-D/I nanoparticles. 

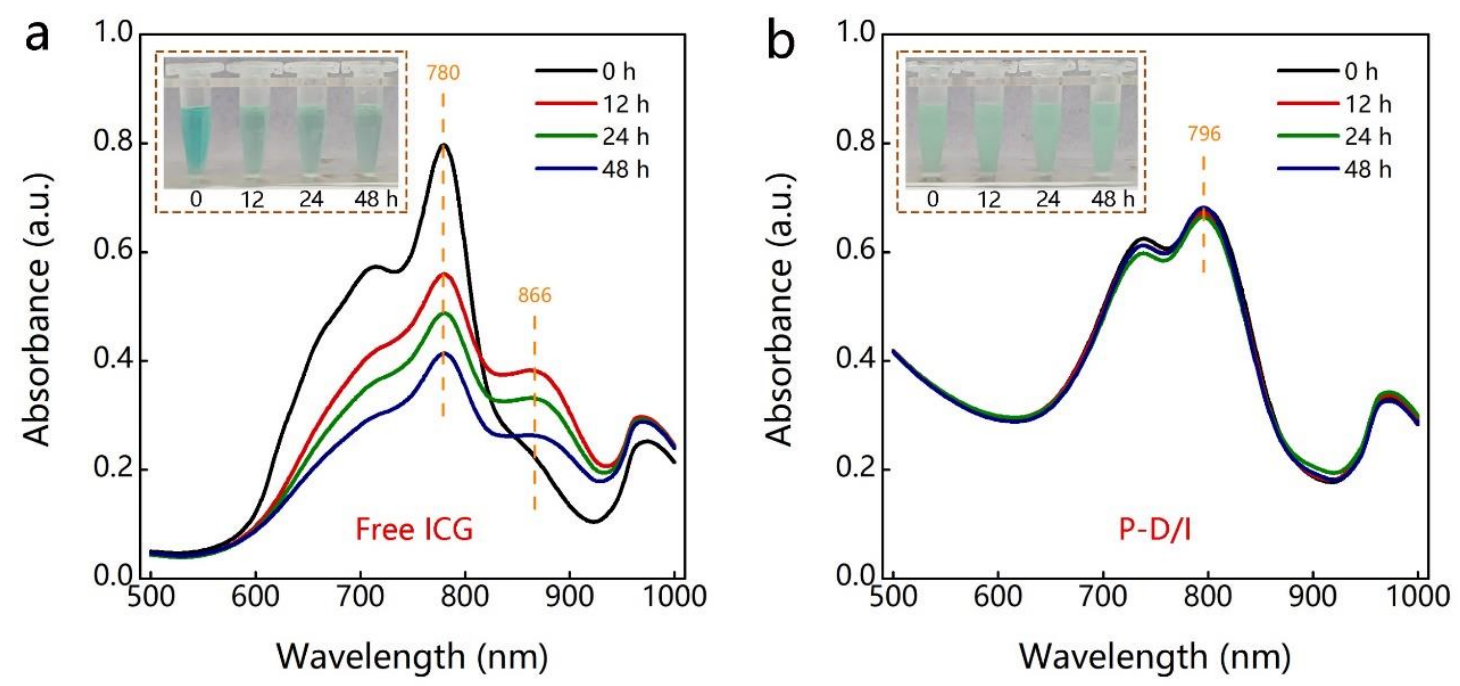

Figure S11. The UV-Vis absorption of free ICG and ICG in P-D/I was recorded at different time points while incubated in PBS at $37^{\circ} \mathrm{C}$. 


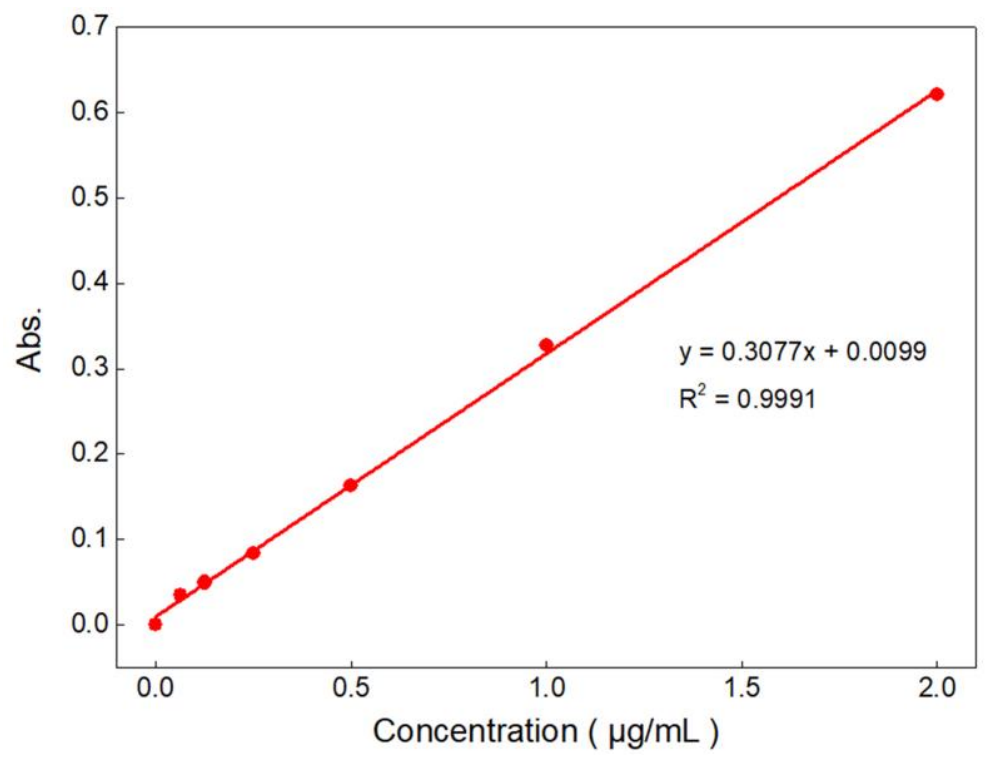

Figure S12. The standard curve of ICG. 


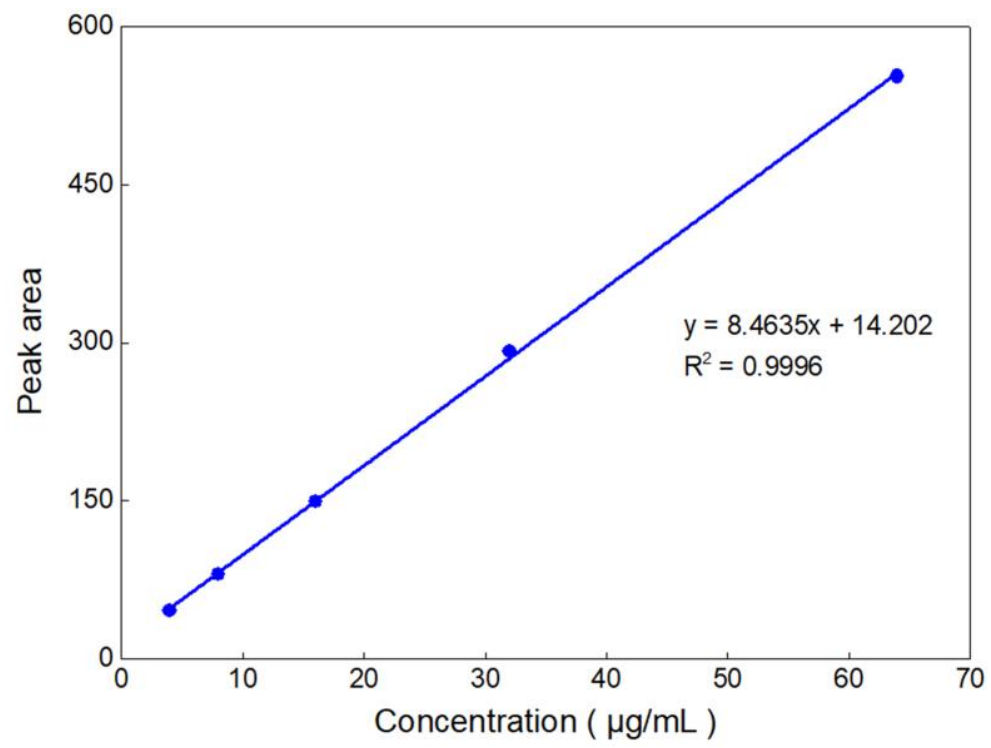

Figure S13. The standard curve of DAS. 


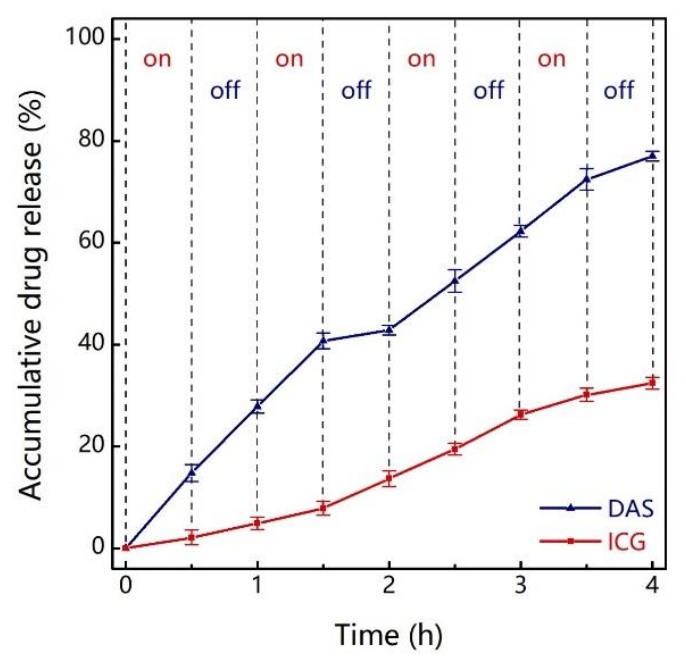

Figure S14. The drug release behavior of DAS and ICG in P-D/I under NIR irradiation $\left(0.5 \mathrm{~W} / \mathrm{cm}^{2}\right.$, $30 \mathrm{~min}$ ). 


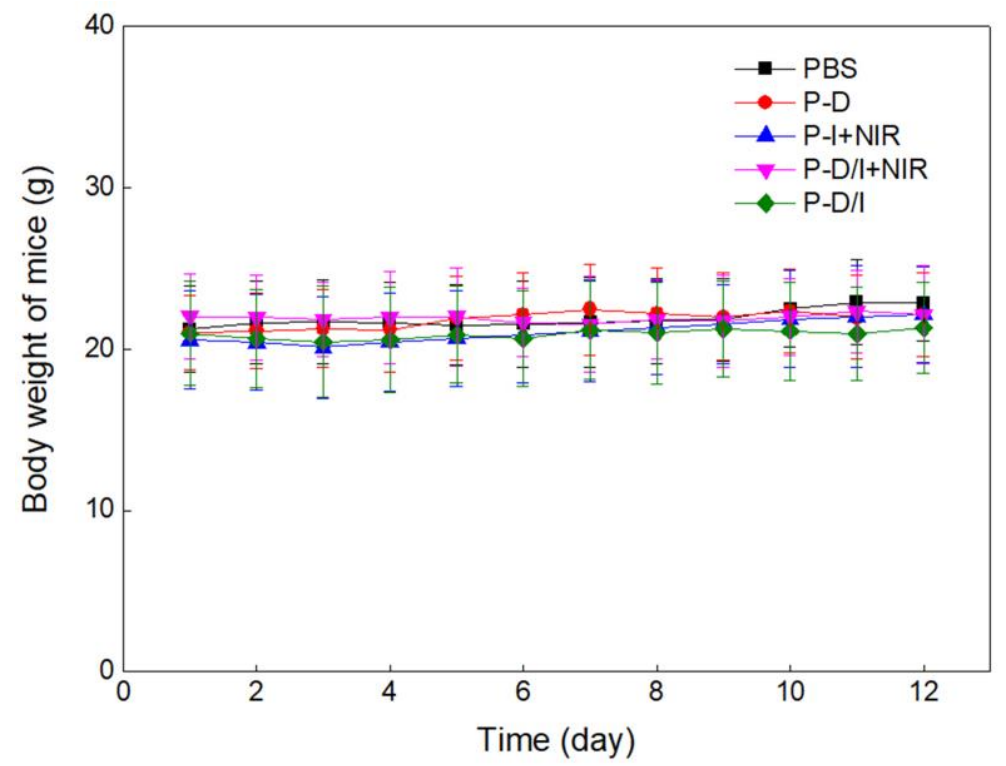

Figure S15. The body weight changes of mice during the treatment $(n=4)$. 


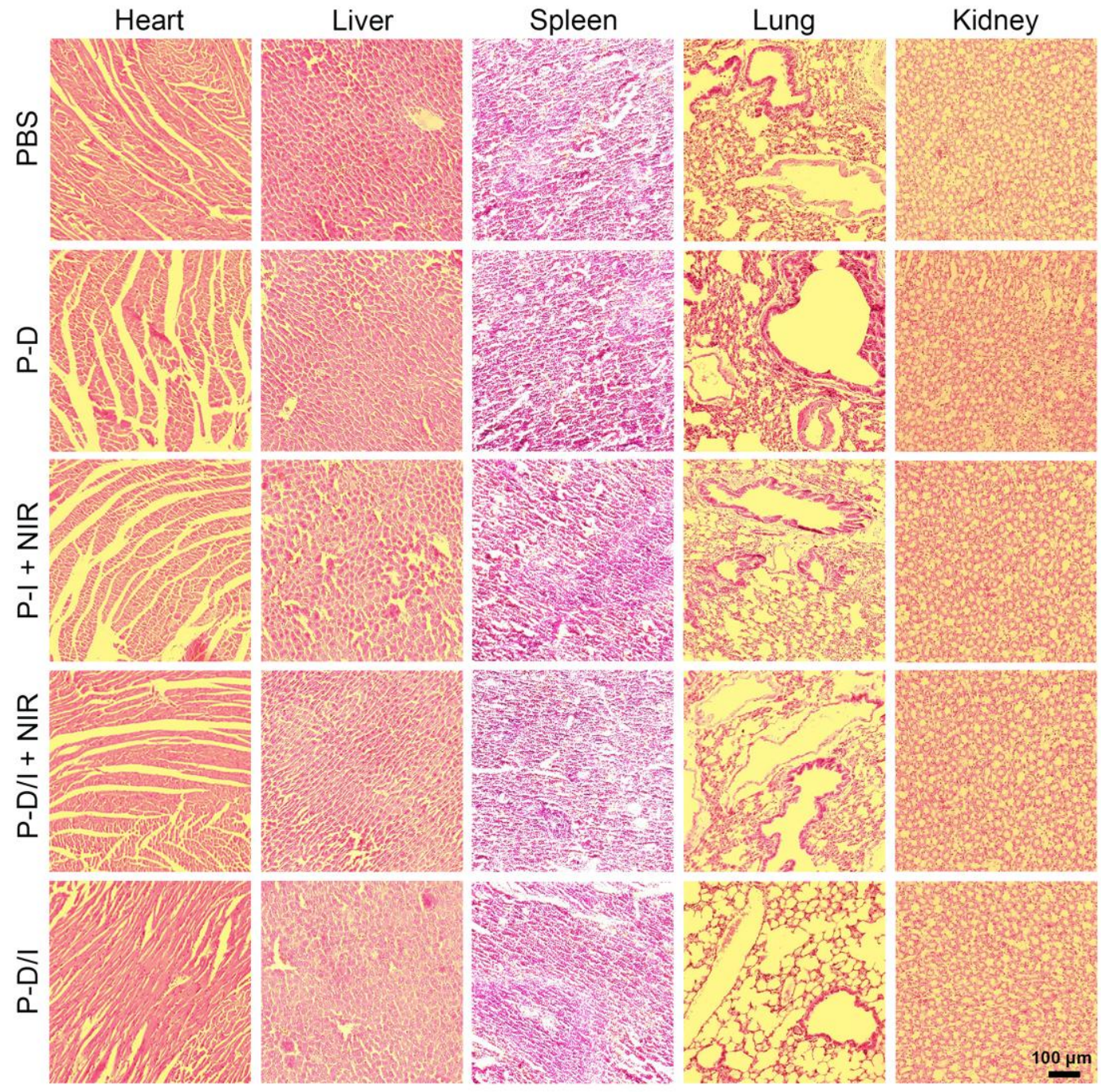

Figure S16. H\&E staining of heart, liver, spleen, lung, and kidney of mice after treatment. 